\title{
A Prospective Study on Clinical Presentation and Surgical Management of Varicose Veins at a Tertiary Care Hospital in Bangalore, India
}

\section{ABSTRACT}

Introduction: Varicose veins are abnormally dilated veins of lower limbs with defective valves. Incidence involves one out of five in the world and the problem is ever growing due to increasing population, increased life span and change in life style. Hence, there is a need to delineate the epidemiology of the varicose veins in the local population which visited the hospital.

Aim: To study the various clinical presentations, management and complications of varicose veins.

Materials and Methods: It was a prospective observational study; conducted by the Department of General surgery at Sri Siddhartha Institute of Medical Sciences and Research Centre, Bangalore, Karnataka, India from September 2018-February 2020. All 75 patients enrolled were evaluated by detailed history, clinical examination and investigations- venous doppler study of the lower limbs, to locate the site of incompetence. All the cases that underwent surgical procedure were followed postoperatively for any complications every one month for development of surgical site infections, after three months for healing of ulcer and at six months for any signs of recurrence. The collected data was entered in Microsoft Excel spread sheet and analysed using descriptive statistics.

Results: The study included 75 cases with primary varicose veins. The age of these patients ranged from 21-69 years. Male to female ratio was $1.5: 1$. Most of them were farmers (48\%) by occupation requiring prolonged hours of standing. All cases presented with dilated veins. The common associated symptoms were pain $(50.7 \%)$ followed by itching (28\%) with slight increased incidence in the left lower limb (50.7\%). Majority of the patients have involvement of long sephenous system (81.3\%). Majority of them (48\%) had combined valvular incompetence. Sapheno-femoral flush ligation with stripping appeared to be the best method of surgical management for incompetence in the long saphenous vein territory. Ten (13.3\%) cases had postoperative complications.

Conclusion: Varicose veins are a common disease, middle age group, males and occupation with prolonged hours of standing are affected the most. Surgical procedures have beneficial effects in minimising morbidity due to varicose vein.

\section{INTRODUCTION}

Varicose veins are dilated, elongated, and tortuous veins. The word "varicose" is derived from the Latin word "varix," which means twisted [1]. Varicosity is the penalty for verticality against gravity [2]. The occurrence of varicose vein of lower limbs is greatly influenced by erect posture of humans. As a result of the erect posture there is impairment of return of venous blood to the heart against gravity which leads to chronic venous insufficiency [3].

Varicose veins have defects in the valves or walls of the superficial venous system or perforating veins. Ageing increases the risk of varicose vein as there is wear and tear of these valves in the veins; other predisposing factors are prolonged standing, intra-abdominal pressure, pregnancy, obesity and heredity [4].

Varicose vein of lower limb is slowly progressive disease, so the patients tend to neglect the mild symptoms and present to the hospital only when there are complications such as pain, oedema, eczema, skin changes and ulceration [5]. Chronic venous insufficiency can be accurately diagnosed by Duplex imaging and Doppler ultrasound. Varicose vein management includes various surgical techniques like stripping, trendelenburg operation, subfascial ligation of perforators, laser, sclerotherapy and radiofrequency ablation $[6,7]$.

Western countries have higher prevalence varicose vein of $15-20 \%$ as the patients have cosmetic concern whereas in India complications of varicose veins brings them to hospital, hence lesser prevalence [8]. So, though common, varicose veins remain as an iceberg phenomenon.
Hence, the present study was undertaken with the aim to study various clinical presentations of varicose veins and their management and with the objectives to study the demographic factors and clinical presentation of patients with varicose veins and to determine the different modalities of treatment of lower limb varicosities utilised in our institute.

\section{MATERIALS AND METHODS}

This was a prospective observational study conducted by the Department of General surgery at Sri Siddhartha Institute of Medical Sciences and Research Centre, a tertiary care hospital from September 2018 to February 2020 after obtaining approval of the Institutional Ethical Committee (SIMS/IEC-12/2018).

Sample size calculation: Sample size was calculated considering the prevalence as 25\%, based on the study conducted by Malhotra SL [9].

Formula for sample size calculation is:

$$
\mathrm{n}=\frac{Z^{2} P(1-P)}{d^{2}}
$$

Z=1.96 for $95 \%$ Confidence Interval

$\mathrm{P}=25 \%$ Prevalence (Study by Malhotra SL)

$1-\mathrm{P}=75 \%$

$\mathrm{d}=10 \%$ Absolute precision

$$
\mathrm{n}=\frac{(1.96)^{2} \times 0.25 \times 0.75}{(0.1)^{2}}
$$

$\mathrm{n}=72$,

a total of 75 patients were included in the present study 
Purposive sampling technique was used and all the cases attending the Outpatient Department (OPD) of general surgery with symptoms of varicose veins were included in the study. After explaining the study in detail informed consent was taken by them. The sociodemographic data was collected in a predesigned semi-structured questionnaire. All enrolled patients were evaluated by detailed history; general examination and clinical examination was done. Some basic and specific investigations- venous doppler study of the lower limbs, to further locate and evaluate the site of incompetence in the lower limb venous system was done.

Inclusion criteria: All patients above 18 years willing to give informed consent with primary lower limb varicose veins with saphenofemoral and/or saphenopopliteal incompetence with or without perforator were included. And also, those with the complications like chronic swelling, pigmentation, eczema, lipodermatosclerosis and venous ulceration were included in the study.

Exclusion criteria: The study excluded pregnant females with varicose veins and also those with secondary varicose veins, recurrent varicose veins, deep venous thrombosis, and other associated peripheral arterial and lymphatic disorders.

Surgical procedures: Striping of long saphenous vein, trendelenberg's operation, subfascial or extra facial ligation of perforators, multiple stab avulsion of long saphenous vein and saphenopopliteal junction ligation procedures were performed. Postoperatively cases were followed-up at one, three and six months for any complications.

\section{STATISTICAL ANALYSIS}

The data collected was entered in Microsoft Excel and statistical software Statistical Package for Social Sciences (SPSS) Version 21.0 was used for statistical analysis. The results were computed by using descriptive statistics like mean and percentage.

\section{RESULTS}

The study included a total 75 patients with primary varicose veins. The age range of these patients was 21-69 years. Most of them (34.7\%) were of the age group 41 to 50 years [Table/Fig-1].

\begin{tabular}{|l|c|c|}
\hline Age groups (years) & No. of cases & Percentage (\%) \\
\hline $21-30$ & 10 & 13.3 \\
\hline $31-40$ & 14 & 18.7 \\
\hline $41-50$ & 26 & 34.7 \\
\hline $51-60$ & 19 & 25.3 \\
\hline$>61$ & 06 & 08 \\
\hline
\end{tabular}

In the study 46 (61.3\%) patients were male patients and 29 (38.7\%) were female patients. Out of 75 patients, most of them were farmers (48\%) by occupation, followed by manual labourer (22.7\%), housewife (18.7\%), teachers (6.7\%), clerk (2.6\%) and tailor (1.3\%) [Table/Fig-2].

\begin{tabular}{|l|c|c|}
\hline Occupation & No. of cases & Percentage (\%) \\
\hline Farmer & 36 & 48 \\
\hline Manual labourer & 17 & 22.7 \\
\hline Housewife & 14 & 18.7 \\
\hline Teacher & 5 & 6.7 \\
\hline Clerk & 2 & 2.6 \\
\hline Tailor & 1 & 1.3 \\
\hline \multicolumn{2}{|l|}{ [Table/Fig-2]: Distribution of study subjects according to occupation ( $\mathrm{N}=75)}$. \\
\hline
\end{tabular}

All the study subjects with varicose veins had the complaint of dilated tortuous veins of the lower extremities other associated symptom most common being pain among 38 patients (50.7\%). Itching was the second most common presenting symptom seen in 21 (28\%) patients. Sixteen cases (21.3\%) had limb oedema, eczema was seen in $13(17.3 \%)$ patients, 9 (12\%) cases presented with an ulcer and lipodermatosclerosis was found in 5 cases (8.33\%) [Table/Fig-3].

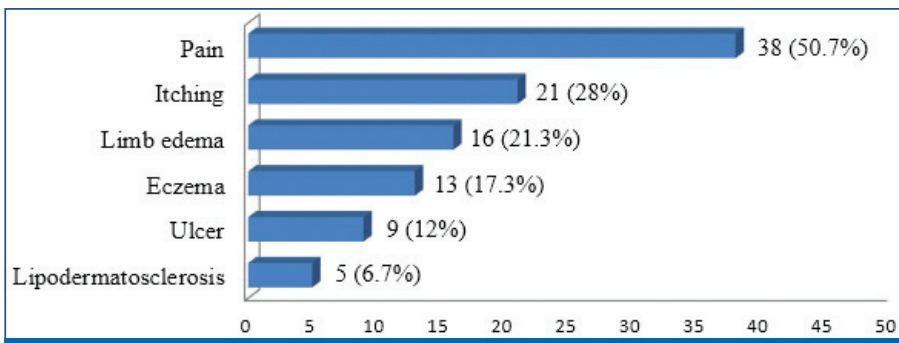

[Table/Fig-3]: Symptom profile $(\mathrm{N}=75)$.

The study showed slight increased incidence in the left lower limb. A total of 38 patients (50.7\%) had left limb involved whereas 29 patients (38.6\%) had right limb involvement. Only 8 patients, (10.7\%) had both the limbs involved [Table/Fig-4]. Majority of the patients (81.3\%) had involvement of Great saphenous system [Table/Fig-5].

\begin{tabular}{|l|c|c|}
\hline Affected limb & No. of cases & Percentage (\%) \\
\hline Left & 38 & 50.7 \\
\hline Right & 29 & 38.6 \\
\hline Both limbs & 08 & 10.7 \\
\hline \multicolumn{2}{|c|}{ [Table/Fig-4]: Distribution of study subjects according to limb affected (N=75). }
\end{tabular}

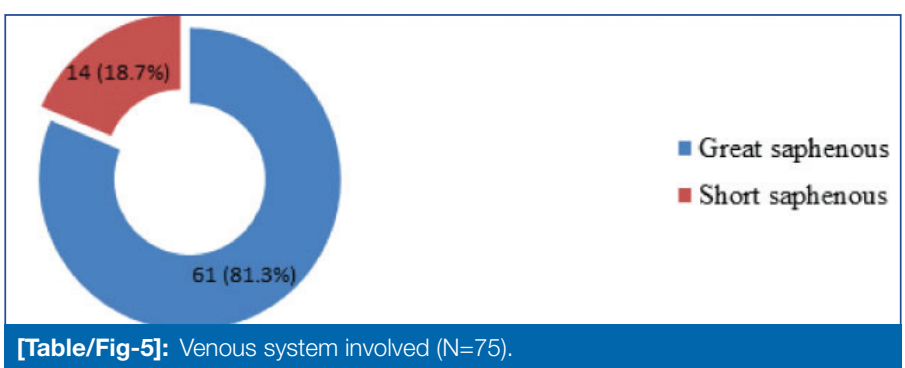

Majority of them (48\%) had combined valvular incompetence. A 25.3\% had isolated perforator incompetence. A 22.7\% patients had isolated sapheno femoral junction incompetence and only $4 \%$ patients had combined saphenofemoral, saphenopopliteal and perforator incompetence [Table/Fig-6].

\begin{tabular}{|l|c|c|}
\hline Site of incompetence & No. patients & Percentage (\%) \\
\hline Sapheno femoral & 17 & 22.7 \\
\hline Saphenofemoral +perforator & 36 & 48 \\
\hline Saphenofemoral+sapheno popliteal+perforator & 3 & 4 \\
\hline Isolated perforator & 19 & 25.3 \\
\hline [Table/Fig-6]: Site of incompetence $(\mathrm{N}=75)$.
\end{tabular}

In this study, except 19 patients who did not have Sapheno femoral incompetence, all other patients underwent Sapheno femoral flush ligation. Nine patients underwent sclerotherapy. Ten patients underwent multiple subfascial perforator ligation and only 3 patients underwent trendelenberg operation with saphenopopliteal junction ligation with multiple subfascial perforator ligation and stripping [Table/Fig-7].

\begin{tabular}{|l|c|c|}
\hline Treatment modality & $\begin{array}{c}\text { No. of } \\
\text { patients }\end{array}$ & $\begin{array}{c}\text { Percentage } \\
\text { (\%) }\end{array}$ \\
\hline Sapheno femoral flush ligation & 17 & 22.7 \\
\hline $\begin{array}{l}\text { Saphenofemoral flush ligation+subfascial perforator } \\
\text { ligation }\end{array}$ & 23 & 30.7 \\
\hline Sapheno femoral flush ligation+stripping & 13 & 17.3 \\
\hline Subfascial perforator ligation & 10 & 13.3 \\
\hline Sclerotherapy & 9 & 12 \\
\hline $\begin{array}{l}\text { Saphenofemoral flush ligation+subfascial perforator } \\
\text { ligation+saphenopopliteal junction ligation+stripping }\end{array}$ & 3 & 4 \\
\hline [Table/Fig-7]: Surgical procedures performed (N=75). & \\
\hline
\end{tabular}


Out of 75 cases operated, 10 (13.3\%) cases had complications. Haematoma was seen in 5 cases (6.6\%), Surgical site infection seen in 3 cases (4\%) and neuritis seen in 2 cases (2.6\%) [Table/Fig-8].

\begin{tabular}{|l|c|c|}
\hline Complication & No. of patients & Percentage (\%) \\
\hline Haematoma & 5 & 6.7 \\
\hline Infection & 3 & 4 \\
\hline Neuritis & 2 & 2.6 \\
[Table/Fig-8]: Postoperative complications (N=75).
\end{tabular}

\section{DISCUSSION}

The present study included 75 patients with primary varicose veins. The age of these patients ranged from 21-69 years. Malhotra SL (1972) in his study had an age range of 18-65 years [9]. Various clinical and epidemiological studies show that varicose veins are a disease of middle age group. The reason might be that it is the period during which a person is most active and is the productive phase of life. The incidence is less before 20 years which can be because of greater elasticity of skin and veins and active muscular movement. The hydrostatic pressure within the venous system gets increased when the person attains his full height and hence, the frequency increases after puberty.

Male to female ratio in the present study was found to be 1.5:1. In the study by Kudchadkar SJ et al., also the ratio was 1.5:1. Less number of females were affected in the present study. This may be due to the fact that in rural females being shy, hesitant to come to hospital for treatment [10]. Moreover, the female, in Indian culture, attire completely covering the legs, may be the cause of negligence and are less worried about the cosmetic appearance.

Occupation of an individual plays a vital role in the occurrence of varicose veins. Occupations with prolonged hours of standing predisposes to varicose veins due to venous stasis [3]. In our study most of the patients were farmers (48\%) by occupation who were been exposed to prolonged hours of standing, about 10 hours per day. Similar results with farmers and housewives being affected the most was seen in the study of Mirji P et al., [11]. In another study, by Jakobsen $\mathrm{BH}$ had $68.3 \%$ of patients with occupation involving prolonged hours of standing [12].

All the patients with varicose veins had the complaint of dilated tortuous veins of the lower extremities. The other complaints include pain, itching, swelling, ulceration and skin changes. In the present study $50.7 \%$ cases had pain as presenting complaint which compares favourably with study conducted by Saarinen $\mathrm{J}$ et al., [13]. However, eczema was seen in $22 \%$ cases in study conducted by Murli N and Navin ID greater than 13\% reported in the present study [14]. In this study, 6.7\% cases presented with lipodermatosclerosis which is greater than $2.5 \%$ cases reported in a study conducted by Robertson $L$ et al., [15]. This may be due to sheer negligence towards minor ailments that the patient land up with complications.

In the present study, there was $50.7 \%$ left limb involvement and $38.6 \%$ right limb involvement was which were well comparable to the study conducted by Dur AHM and Mackay AJC. which showed $51.5 \%$ involvement of left limb and $48.5 \%$ involvement of right limb [16]. The increased incidence of varicosity noted on left side as the right common iliac artery traverses over the left common iliac vein, the venous drainage has a more tortuous course in the left lower limb [17].

In 61 cases (81.3\%), great saphenous vein was affected and short saphenous vein was affected in 14 cases (18.7\%) which is comparable to study conducted by Delbe and Mocquet with $98 \%$ involvement of great saphenous vein and only $2 \%$ involvement of short saphenous vein [18].

In the study, $74.7 \%$ of patients had perforator incompetence similar results with $68 \%$ perforator incompetence was seen in study done by Labropoulos $\mathrm{N}$ et al., [19]. In this study, 39 (52\%) cases had combined superficial and perforator incompetency and 19 (25.3\%) had isolated superficial incompetency which is almost comparable to the $65 \%$ of combined superficial and perforator incompetency and $22.33 \%$ isolated superficial incompetency obtained in study by Lees TA and Lambert D study [20].

In the present study 10 (13.3\%) had postoperative complications. Among them $6.6 \%$ had haematoma and $4 \%$ had postoperative wound infection. Similar observation was seen in study done by Janugade HB et al., [21].

\section{Limitation(s)}

Generalisation of the study results to entire population cannot be done as it a hospital based study.

\section{CONCLUSION(S)}

It was a prospective study where data was collected at regular interval. This study increased the awareness among the study subjects about the lifestyle which leads to the development of varicose veins and to take measure to avoid them. Varicose veins are a common disease among middle age males whose occupation involves prolonged hours of standing and who are affected the most. Usually, presenting symptoms are dilated veins in the limb associated with pain, itching, oedema, pigmentation, eczema and ulceration. Long saphenous system is most commonly affected. Diagnosis by clinical test and venous study Doppler has high sensitivity. Surgical procedures have beneficial effects in minimising morbidity due to varicose vein.

\section{REFERENCES}

[1] McCollum P, Chapter I. Venous disorders. In: Bailey H, Love McN, editors. Bailey and Love's Short Practice of Surgery. $26^{\text {th }}$ ed. Boca Raton, FL: CRC Press; 2013: 903.

[2] Shenoy KR. Varicose veins, Deep vein thrombosis: Manipal manual of surgery. 2nd ed. New Delhi: CBS Publishers \& Distributors. 2005,90-100.

[3] Dodd H, Cockett FB. The Pathology and Surgery of the Veins of the Lower Limbs. London: Churchill Livingstone; 1956:28-64.

[4] Bradbury A, Evans C, Allan P, Lee A, Ruckley CV, Fowkes FG. What are the symptoms of varicose veins? Edinburgh Vein Study cross sectional population survey. BMJ. 1999;318(7180):353-56.

[5] Callam MJ. "Varicose Veins" in Essential surgical practice, Module 34. $4^{\text {th }}$ ed. London: Hodder Arnold Publications; 2002:879-890.

[6] Campbell B. Varicose veins and their management. BMJ. 2006;333(7562):287-92.

[7] Van den Bremer J, Moll FL. Historical overview of varicose vein surgery. Ann Vasc Surg. 2010;24(3):426-32.

[8] Callam MJ. Epidemiology of varicose veins. Br J Surg. 1994;81(2):167-73.

[9] Malhotra SL. An Epidemiological study of varicose veins in Indian rail road workers from the South and North of India, with special reference to the causation and prevention of varicose veins. Int. J Epidemiol. 1972;1(2):177-83.

[10] Kudchadkar SJ, Chodankar SU, Noronha FP. Clinicopathological study of varicose veins. MGM J Med Sci 2019; 6(4):157-164.

[11] Mirji P, Emmi S, Joshi C. Study of clinical features and management of varicose veins of lower limb. Journal of Clinical and Diagnostic Research. 2011;5(7):1416-20.

[12] Jakobsen $\mathrm{BH}$. The value of different forms of treatment for varicose veins. $\mathrm{Br} \mathrm{J}$ Surg. 1979;66(3):182-84

[13] Saarinen J, Suominen V, Heikkinen M, Saaristo R, Zeitlin R, Vainio J, et al. The profile of leg symptoms, clinical disability and reflux in legs with previously operated Varicose disease. Scand J Surg. 2005;94(1):51-55.

[14] Murli NL, Navin ID. Classical varicose vein surgery in a diverse ethnic community. Med J Malaysia. 2008;63(3):193-98.

[15] Robertson L, Lee AJ, Gallagher K, Carmichael SJ, Evans CJ, McKinstry BH, et al. Risk factors for chronic ulceration in patients with varicose veins: A case control study. J Vasc Surg. 2009;49(6):1490-98.

[16] Dur AHM, Mackay AJC. Duplex assessment of clinically diagnosed chronic venous insufficiency. Br J Surg. 1992;79:155-61.

[17] Mekky S, Schilling RSF, Walford J. Varicose veins in women cotton workers: An epidemiological study in England and Egypt. $\mathrm{Br}$ Med J. 1969;2(5657):591-95.

[18] Delbe and Mocquet. Varicose veins and deep vein thrombosis: Epidemiology and suggested aetiology. Br Med J. 2005;2:556. 
[19] Labropoulos N, Giannoukas AD, Delis K, Mansour MA, Kang SS, Nicolaides AN, et al. Where does venous reflux start? J Vasc Surg. 1997;26(5):736-42.

[20] Leese TA, Lambert D. Patterns of venous reflux in limbs with skin changes associated with chronic venous insufficiency. Br J Surg. 1993;80(6):725-28.
[21] Janugade HB, Patil BP, Tata NH, Saygaonkar HV, Janugade DH, Dokania V, et al. Clinical profile and management of lower limb varicose veins. J Evolution Med Dent Sci. 2017;6(20):1615-22.

\section{PARTICULARS OF CONTRIBUTORS:}

1. Assistant Professor, Department of Surgery, Sri Siddhartha Institute of Medical Sciences and Research Centre, Bangalore, Karnataka, India

2. Professor and Head, Department of Surgery, Sri Siddhartha Institute of Medical Sciences and Research Centre, Bangalore, Karnataka, India.

\section{NAME, ADDRESS, E-MAIL ID OF THE CORRESPONDING AUTHOR:}

Dr. Vikram Ramamurthy,

Assistant Professor, Department of Surgery, Sri Siddhartha Institute of Medical Sciences

and Research Centre, T. Begur, Bangalore, Karnataka, India.

E-mail: vikramrn90@gmail.com

\section{PLAGIARISM CHECKING METHODS: [Jain Het al.]}

- Plagiarism X-checker: Feb 16, 2021

- Manual Googling: May 01, 2021

- iThenticate Software: May 13, 2021 (16\%)
ETYMOLOGY: Author Origin

Date of Submission: Feb 11, 2021

- Financial or Other Competing Interests: None

- Was Ethics Committee Approval obtained for this study? Yes

- Was informed consent obtained from the subjects involved in the study? Yes

- For any images presented appropriate consent has been obtained from the subjects. NA of Peer Review: Mar 24, 2021

Date of Acceptance: May 03, 2021 